\title{
Viabilidade celular da mucosa do intestino delgado de ratos, após correção de choque hipovolêmico com solução de $\mathrm{NaCl} 7,5 \%^{1}$
}

\author{
Marcus Vinicius Henriques Brito ${ }^{2}$ \\ Amaury José Texeira Nigro ${ }^{3}$ \\ Edna Frasson de Souza Montero ${ }^{4}$ \\ José Luiz Martins do Nascimento ${ }^{5}$ \\ Paula Roberta Ferreira da Silva ${ }^{6}$ \\ Roberta Bianca Peres Siqueira ${ }^{6}$
}

Brito MVH, Nigro AJT, Montero EFS, Nascimento JLM, Silva PRF, Siqueira RBP. Viabilidade celular da mucosa do intestino delgado de ratos, após correção de choque hipovolêmico com solução de $\mathrm{NaCl}$ 7,5\%. Acta Cir Bras [serial online] 2003 Jul-Ago;18(4). Disponível em URL: http:/ /www.scielo.br/acb.

RESUMO - Objetivo: Estudar o efeito da correção volêmica com diferentes tipos de solução, na mucosa do intestino delgado de ratos. Métodos: Foram utilizados 120 ratos Wistar (Rattus norvegicus albinus), machos, adultos, com peso individual entre 310 e $410 \mathrm{~g}$, oriundos do Instituto Evandro Chagas de Belém do Pará, submetidos a período de adaptação por 15 dias, recebendo água e ração ad libitum, durante todo o experimento. Os animais foram distribuídos em: Grupo Padrão $(\mathrm{P})$, Grupo Choque (C), Grupo Solução Fisiológica (SF) e Grupo Solução Hipertônica (SH), com 30 animais cada. Estes foram divididos em subgrupos com 10 animais cada, de acordo com o dia de pós-operatório (DPO) previsto para a eutanásia dos animais, $\left(1^{\circ}, 3^{\circ}\right.$ ou $\left.7^{\circ} \mathrm{DPO}\right)$, sendo após esta, colhido material para realização de teste de absorvância pelo MTT em todos os animais. Resultados: $\mathrm{O}$ grupo SF apresentou menores índices de viabilidade celular comparado aos grupos $\mathrm{SH}$ e $\mathrm{C}$ $(\mathrm{p}<0.05)$. Conclusão: A correção volêmica com solução de cloreto de sódio a $7.5 \%$ levou a manutenção de maior quantidade de células viáveis, no intestino delgado em ratos no $7^{\circ}$ dia do experimento.

DESCRITORES - Sobrevivência celular. Choque. Soluções hipertônicas. Ratos.

\section{Introdução}

Estados de choque e suas conseqüências como a translocação bacteriana seguida de sepsis, insuficiência de múltiplos órgãos e sistemas (IMOS) e síndrome da resposta inflamatória sistêmica (SIRIS) são ainda hoje causas de morte em inúmeras situações traumáticas. ${ }^{1}$
Embora diversas teorias tenham sido lançadas a respeito destes estados, grandes avanços no conhecimento de sua fisiopatologia somente começaram a surgir após a II Grande Guerra quando BEECHER (1952) publicou seus estudos a respeito de estados hipovolêmicos. Propôs como terapêutica para tais quadros a reposição rápida do volume perdido. ${ }^{2}$

1. Trabalho realizado no Laboratório de Cirurgia Experimental da Universidade do Estado do Pará/LCE-UEPA, com o apoio da Universidade Federal de São Paulo, Instituto Evandro Chagas e Universidade Federal do Pará.

2. Professor Doutor Adjunto do Departamento de Medicina Integrada da UEPA; Coordenador do LCE da UEPA; Presidente da SOBRADPEC-Regional Pará.

3. Professor Titular do Departamento de Cirurgia e Coordenador do Curso de Pós-Graduação em Técnica Operatória e Cirurgia Experimental da Universidade Federal de São Paulo, EPM.

4. Professora Adjunta Visitante do Departamento de Cirurgia da Universidade Federal de São Paulo, EPM.

5. Professor Doutor Adjunto do Departamento de Fisiologia do Centro de Ciências Biológicas da Universidade Federal do Pará.

6. Acadêmicas do Curso de Medicina da UEPA; Estagiárias do LC E-UEPA. 
O grande fator limitante na recuperação destes pacientes foi a insuficiência respiratória pós-traumática, hoje conhecida como "Síndrome da Angústia Respiratória Aguda" (SARA). ${ }^{2}$

Na década de 80, após os estudos experimentais de VELASCO, PONTIERI, ROCHA E SILVA Jr. e LOPES (1980), foi iniciada a utilização clínica da solução hipertônica de cloreto de sódio a 7,5\% (SH). Diversos autores ${ }^{4}$ têm estudado seus efeitos, descrevendo sua superioridade em relação às reposições volêmicas clássicas, realizadas com solução fisiológica a $0,9 \%$ (SF) ou soluções de ringer, com ou sem lactato.

Dentre as vantagens da SH, são citadas a utilização de baixos volumes, que chegam a $1 \backslash 13$ do volume de SF descrito como necessário à recuperação do volume plasmático e dos níveis da tensão arterial; melhora do débito cardíaco por aumento da pré-carga, contestada por alguns ${ }^{4}$; redução da formação do edema intersticial pós-traumática no cérebro e pulmão ${ }^{4}$, resultando em uma menor morbi-mortalidade em pacientes graves.

Possivelmente estas vantagens resultam da transferência de líquidos, respectivamente, dos espaços intracelular e intersticial para o espaço intravascular, estando ainda envolvidos fatores neuro-humorais ${ }^{5}$.

Neste sentido, pesquisas atuais concentram-se em estudar principalmente os efeitos hemodinâmicos e cardio-circulatórios das reposições com soluções hipertônicas, assim como suas repercussões no coração ${ }^{1}$, pulmão ${ }^{7}$, cérebro ${ }^{3}$ e rins. $^{4}$

Embora em estados hipovolêmicos haja recuperação pressórica com a utilização da $\mathrm{SH}$, nesta situação, devido a seu mecanismo de ação ${ }^{4}$, poderia estar presente desidratação intracelular e intersticial, como sugerido por SZTARK, GÉKIÈRE, DABADIE (1997), levando teoricamente, a um maior sofrimento tecidual e citotoxicidade por acúmulo de catabólitos.

Estes, por sua vez poderiam acarretar um aumento de lesão tecidual, principalmente em órgãos como o intestino, onde a maior destruição das vilosidades e diminuição da barreira mucosa, induz a uma maior incidência de translocação bacteriana, sepsis, SIRIS e conseqüente óbito por IMOS. ${ }^{6}$

$\mathrm{Na}$ literatura consultada, não foram encontrados estudos correlacionando especificamente o efeito da reposição volêmica com solução hipertônica e graus de viabilidade celular, após estados de choque. Portanto, decidiu-se estudar experimentalmente as repercussões na mucosa do intestino delgado, causadas pela correção volêmica com diferentes soluções de reposição.

\section{Métodos}

Foram utilizados, 120 ratos Wistar ( Rattus norvegicus albinus ), machos, adultos, com peso individual variando entre 310 e $410 \mathrm{~g}$, oriundos do Instituto Evandro Chagas de Belém do Pará ( Belém Pará ), adaptados ao Laboratório de Cirurgia Experimental da Universidade do Estado do Pará - UEPA, por 15 dias antes do início do experimento, recebendo água e ração ad libitum, sendo mantidos em ambiente controlado.

Os animais foram distribuídos ao acaso, em grupos e subgrupos a saber:

\section{Grupo Padrão (P)}

Grupo de animais utilizados na determinação do Padrão de normalidade da viabilidade celular. (n=30)

\section{Grupo Choque ( C )}

Grupo de animais submetidos a sangria de $45 \%$ da volemia, sem correção posterior. $(\mathbf{n}=\mathbf{3 0})$

\section{Grupo Solução Fisiológica (SF)}

Grupo de animais submetidos a sangria de $45 \%$ da volemia, seguida de reposição volêmica com $32 \mathrm{ml} /$ $\mathrm{kg}$ de peso de solução fisiológica de cloreto de sódio a $0,9 \%$. $(\mathbf{n}=\mathbf{3 0})$

\section{Grupo Solução Hipertônica (SH)}

Grupo de animais submetidos a sangria de $45 \%$ da volemia, seguida de reposição volêmica com $4 \mathrm{ml} /$ $\mathrm{kg}$ de peso de solução hipertônica de cloreto de sódio a $7,5 \%$. $(\mathbf{n}=\mathbf{3 0})$

Os grupos foram divididos em subgrupos, com 10 animais cada, de acordo com o dia de pós-operatório (DPO) previsto para a eutanásia dos animais $\left(1^{\circ}, 3^{\circ} \mathrm{e} 7^{\circ}\right.$ DPO). Sendo após esta, coletado material para realização de teste de absorvância.

\section{Procedimentos}

Os animais foram submetidos à anestesia inalatória de éter etílico com o auxílio do vaporizador artesanal de éter. ${ }^{7}$ Subseqüentemente, foi realizada a dissecção e cateterismo da artéria carótida direita, com auxílio de material microcirúrgico e cateter siliconizado, afim de se ter acesso ao sistema arterial.

Então os animais foram submetidos a heparinização sistêmica com 0,4 ml de solução de heparina (100 UI, 
diluídas em 0,4 ml de água destilada), sendo utilizados $0,1 \mathrm{ml}$ na heparinização prévia do cateter e os $0,3 \mathrm{ml}$ restantes injetados por via intra-arterial imediatamente após a cateterização da artéria carótida.
O volume de sangue por minuto, a ser retirado de cada animal, foi calculado com base na volemia, utilizando parâmetros determinados por YALE e TORHORST (1972).

\begin{tabular}{|c|c|c|c|c|}
\hline$\underline{\mathrm{P} \times 6}=\mathrm{V}_{\text {mia }}$ & $\Rightarrow$ & $\underline{\mathrm{V}}_{\operatorname{mia}} \times 45=\mathrm{VS}$ & $\Rightarrow$ & $\underline{\mathrm{VS}}=\mathrm{VS} / \mathrm{min}$ \\
\hline 100 & & 100 & & 10 \\
\hline$P$ & $=$ & \multirow{4}{*}{\multicolumn{3}{|c|}{$\begin{array}{l}\text { peso corpóreo do animal em gramas. } \\
\text { volemia do animal em mililitros. } \\
\text { volume de sangue a ser retirado, em mililitros. } \\
\text { volume de sangue a ser retirado por minuto, em mililitros. }\end{array}$}} \\
\hline $\mathrm{V}_{\text {mia }}$ & $=$ & & & \\
\hline VS & $=$ & & & \\
\hline $\mathrm{VS} / \mathrm{min}$ & $=$ & & & \\
\hline
\end{tabular}

O choque hipovolêmico foi obtido pela aspiração contínua em seringa de vidro $(20 \mathrm{ml})$, de $45 \%$ da volemia do animal, realizada em tempo fixo de 10 minutos, via cateter arterial, posicionado na artéria carótida.

Em todos os grupos estudados, foi padronizada a reposição volêmica na taxa de $1 \mathrm{ml} / \mathrm{min}$, a exceção dos grupos $\mathrm{P}$ e $\mathrm{C}$, nos quais a reposição não foi realizada.

No grupo SF, a reposição foi realizada com solução de cloreto de sódio a $0,9 \%$, em volume correspondente a $32 \mathrm{ml} / \mathrm{kg}$ de peso corpóreo do animal, e no grupo $\mathrm{SH}$ foi utilizada solução hipertônica de cloreto de sódio a $7,5 \%$, em volume correspondente a $4 \mathrm{ml} / \mathrm{kg}$ de peso corpóreo do animal.

O tempo destinado a cada procedimento, realizado ou não, foi somado aos demais, tendo duração aproximada de 75 minutos, independentemente do grupo do animal.

Após recuperação anestésica os animais receberam água e ração ad libitum. Sendo que os animais que morreram no pós-operatório foram substituídos por outros até obtenção do número de animais pré - determinados para cada grupo.

Em data preestabelecida $\left(1^{\circ}, 3^{\circ}\right.$ e $\left.7^{\circ} \mathrm{DPO}\right)$, os animais foram anestesiados seguindo técnica descrita anteriormente, sendo realizada laparotomia xifo-pubiana para coletada do material para análise de viabilidade celular.

Foram preparados tubos de ensaio tipo Eppendorf de 1,5cc, contendo 550 microlitros $(\mathrm{ml})$ de solução salina tamponada (PBS), no qual foram adicionados 55 ml de solução de Methyl Thiazolyl Blue (MTT), o qual é preparado pela adição de $0,005 \mathrm{~g}$ do sal de MTT em $1 \mathrm{ml}$ de solução salina tamponada com fosfato.

Com auxílio de um "punch" dermatológico de 3,0 $\mathrm{mm}$ de diâmetro, foram retirados cinco fragmentos circulares do íleo terminal contendo todas suas túnicas, para verificação da viabilidade celular. Foi padronizado como o local de coleta, o segmento de $1,5 \mathrm{~cm}$ a montante do ceco, à média distância entre as bordas mesentérica e antimesentérica.

Imediatamente após sua retirada, cada peça foi introduzida em tubo de ensaio previamente preparado com MTT e mantida em banho maria a $37^{\circ} \mathrm{C}$ por duas horas.

Após retirada do material para análise, os animais foram submetidos à eutanásia por dose inalatória letal de éter etílico.

Ao final das duas horas, no Laboratório de Neurofisiologia da Universidade Federal do Pará, foi introduzido no tubo de ensaio, $400 \mathrm{ml}$ de ácido isopropílico, sendo aguardados 5 minutos para a digestão tissular, após o que foi realizada masseração do tecido e homogeneização da solução em homogeneizador elétrico para tubos de ensaio.

Após 30 minutos da adição do ácido isopropílico em cada tubo de ensaio, $1 \mathrm{ml}$ da solução foi levado à leitura em espectrofotômetro calibrado em comprimento de onda de $570 \mathrm{hm}$, sendo realizadas cinco aferições, cujos resultados foram anotados no protocolo do trabalho, e sua média aritmética adotada como o resultado da absorvância de cada animal.

\section{Estudo estatístico}

O estudo estatístico dos resultados obtidos nesta pesquisa foi realizado no Departamento de Medicina Preventiva, Disciplina de Bioestatística da Universidade Federal de São Paulo, Escola Paulista de Medicina.

Foi utilizado o teste de análise de variância por postos de KRUSKAL-WALLIS (SIEGEL, 1975).

Foi fixado em 0,05 ou $5 \%$ ( a $£ 0,05$ ) o nível para rejeição da hipótese de nulidade em todos os testes aplicados. 


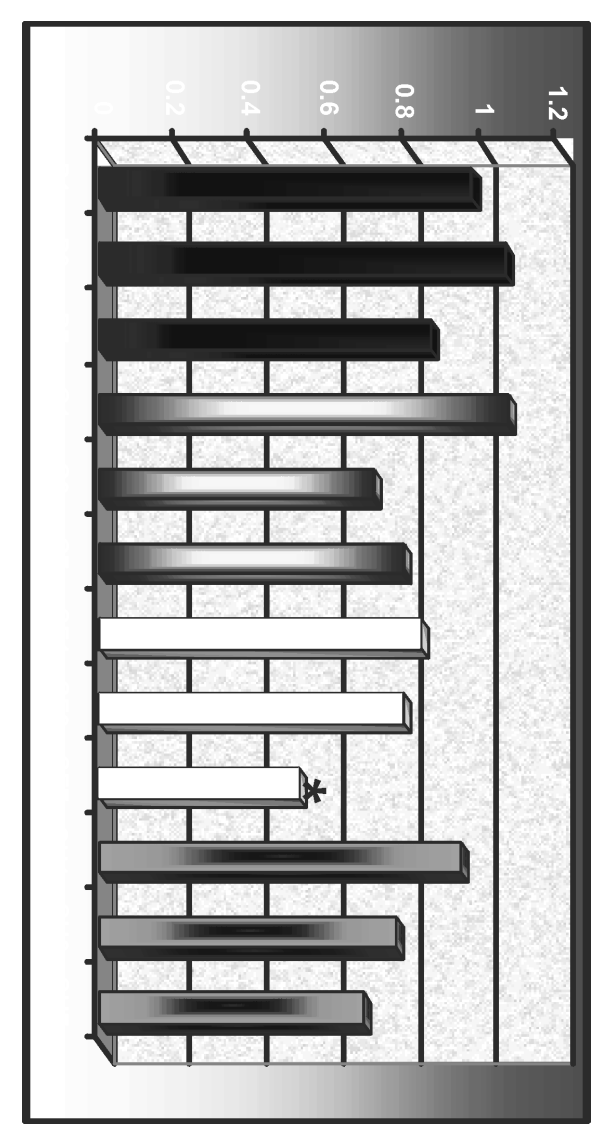




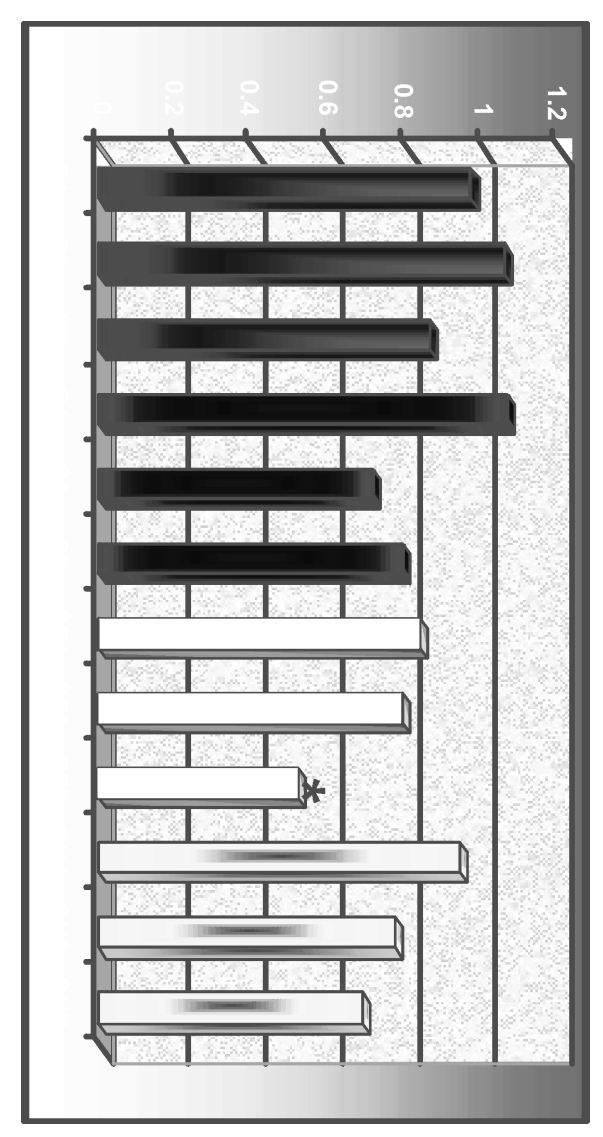




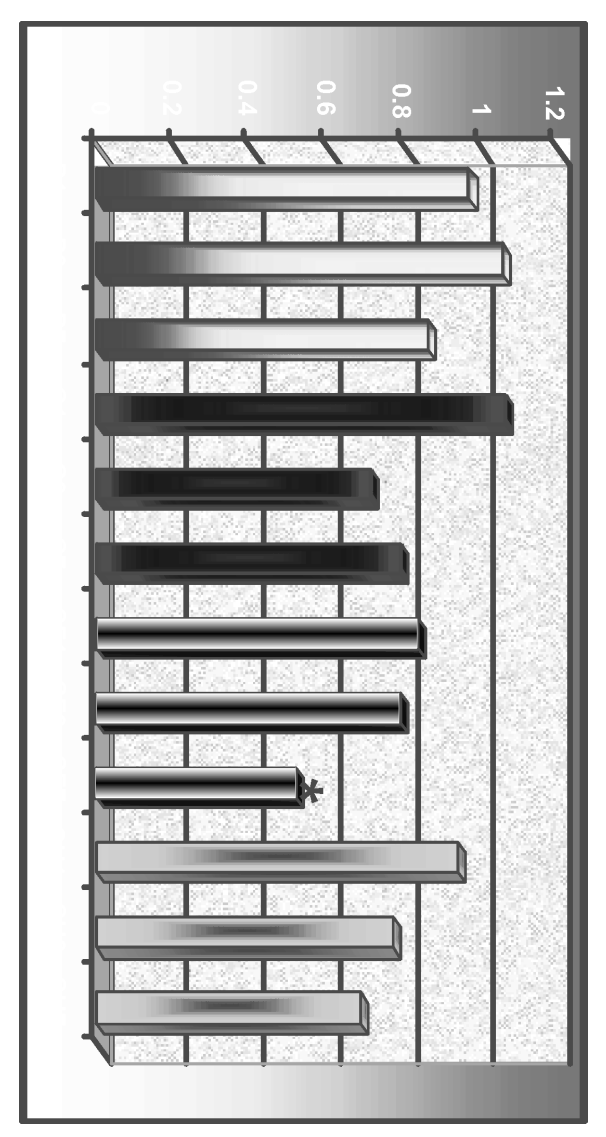


Viabilidade celular da mucosa do intestino delgado de ratos, após correção de choque hipovolêmico com solução de NACL 7,5\%

\section{Resultados}

TABELA 1 - Valores de absorvância do MTT de cada animal, segundo os grupos e subgrupos do experimento.

\begin{tabular}{|c|c|c|c|c|c|c|c|c|c|c|c|c|}
\hline & \multicolumn{3}{|c|}{$\mathbf{P}$} & \multicolumn{3}{|c|}{ C } & \multicolumn{3}{|c|}{ SF } & \multicolumn{3}{|c|}{ SH } \\
\hline & P1 & P3 & P7 & C1 & $\mathrm{C3}$ & C7 & SF1 & SF3 & SF7* & SH1 & SH3 & SH7 \\
\hline & 1,004 & 1,928 & 0,991 & 0,842 & 0,884 & 0,758 & 0,770 & 0,835 & 0,506 & 0,735 & 0,630 & 0,520 \\
\hline & 0,790 & 1,419 & 0,580 & 0,408 & 1,031 & 0,873 & 0,743 & 0,715 & 0,652 & 0,914 & 0,678 & 0,801 \\
\hline & 0,510 & 1,580 & 0,921 & 0,940 & 0,403 & 0,634 & 0,984 & 0,376 & 0,681 & 1,005 & 0,521 & 0,666 \\
\hline & 1,067 & 0,808 & 1,239 & 1,220 & 0,336 & 0,781 & 0,847 & 0,651 & 0,722 & 0,887 & 0,876 & 0,552 \\
\hline & 0,878 & 0,810 & 0,925 & 1,588 & 0,611 & 0,874 & 0,866 & 0,932 & 0,431 & 1,098 & 0,788 & 0,796 \\
\hline & 1,882 & 0,870 & 0,675 & 1,096 & 0,448 & 0,754 & 0,893 & 0,956 & 0,415 & 0,884 & 0,879 & 0,667 \\
\hline & 0,736 & 1,005 & 0,451 & 1,442 & 1,057 & 0,934 & 0,885 & 0,782 & 0,264 & 0,879 & 0,789 & 0,710 \\
\hline & 0,644 & 0,805 & 1,012 & 0,732 & 0,696 & 0,872 & 0,823 & 1,091 & 0,630 & 1,110 & 0,979 & 0,820 \\
\hline & 0,996 & 0,788 & 1,015 & 0,972 & 0,683 & 0,754 & 0,818 & 0,764 & 0,565 & 0,917 & 0,646 & 0,515 \\
\hline & 1,024 & 0,559 & 0,817 & 1,390 & 0,989 & 0,680 & 0,750 & 0,831 & 0,308 & 1,004 & 0,961 & 0,845 \\
\hline Média & 0,971 & 1,057 & 0,863 & 1,063 & 0,714 & 0,791 & 0,838 & 0,793 & 0,517 & 0,943 & 0,775 & 0,689 \\
\hline
\end{tabular}

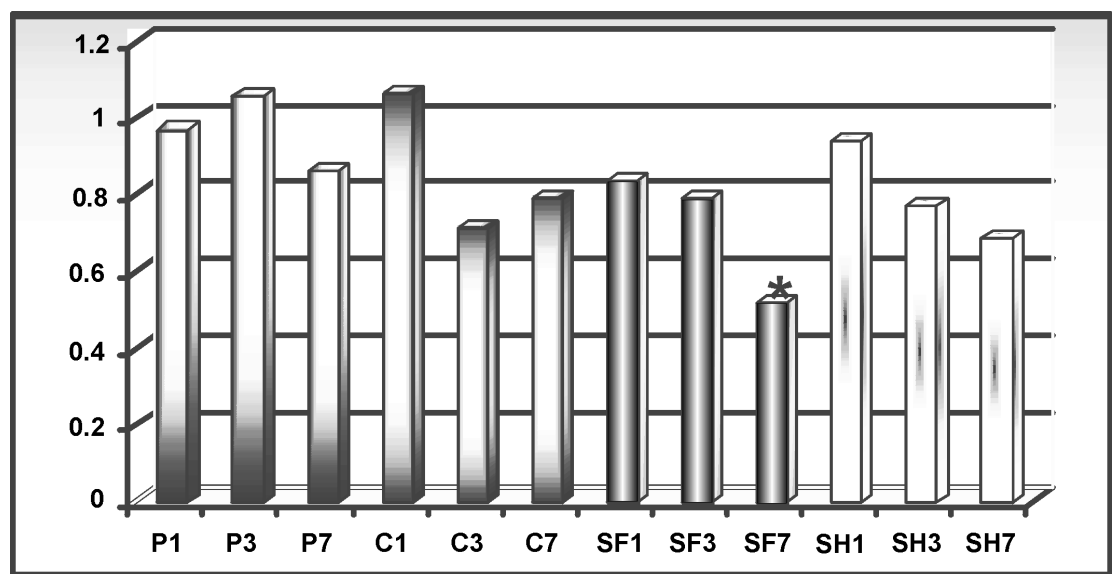

FIGURA 1 - Média dos valores de absorvância do MTT, segundo os subgrupos do experimento.

\section{Discussão}

Nas últimas duas décadas, a evolução do conhecimento fisiopatológico dos estados de choque hipovolêmico $^{10}$, SARA $^{2}$ e SIRIS ${ }^{1}$, fornecidos pela biologia molecular, e melhor compreensão das lesões de isquemia e reperfusão, em muito melhoraram as perspectivas no tratamento de pacientes graves. ${ }^{11}$

Embora muito se tenha descoberto, vários pontos permanecem obscuros ou sob suspeita.

No presente trabalho, a fim de verificar se a solução hipertônica promove efeitos benéficos à mucosa intesti- nal, em comparação às soluções isotônicas, foram realizadas reposições da volemia com fluidos de diferentes osmolaridades, visto ser descrita diminuição significante da perfusão em vilosidades intestinais, como resultado da maior expansão do volume intravascular promovida por soluções hipertônicas. ${ }^{1}$

Estados de hipoperfusão em segmentos intestinais, na dependência de sua intensidade e duração, poderiam levar ao sofrimento isquêmico da túnica mucosa, promovendo conseqüências desastrosas como a translocação bacteriana, SIRIS e IMOS. ${ }^{1}$ 
Os animais do grupo $\mathrm{SF}$, e dos grupos $\mathrm{SH}$, embora recebendo volumes diferentes da solução de $\mathrm{NaCl}$ (1 / 8), em todos, foi disponibilizada a mesma quantidade de cloreto de sódio, pois $1 \mathrm{ml}$ de $\mathrm{SH} 7,5 \%$ e $8 \mathrm{ml}$ de SF $0,9 \%$ possuem aproximadamente $0,075 \mathrm{~g}$ de $\mathrm{NaCl}$.

Para demonstrar o efeito da correção volêmica com os diferentes tipos de solução, na mucosa do intestino delgado, foi estudado o índice de viabilidade celular.

Com este intuito, foi utilizado nesta pesquisa o método colorimétrico para avaliação de crescimento e sobrevivência celular para mamíferos, com o Methyl Thiazolyl Blue (MTT), um sal tetrazólico ${ }^{12}$, de fórmula $\mathrm{C}_{18} \mathrm{H}_{16} \mathrm{~N}_{5} \mathrm{SBr}$, e peso molecular 414,3 UA. que detecta somente células metabolicamente ativas, e não as inativas ou mortas, devido ao seu mecanismo de ação. ${ }^{8}$

De cor amarelo ouro, quando este sal é adicionado às células vivas, sofre clivagem por mitocôndrias ativas, passando a apresentar cor azul escuro. A solução resultante é então lida por espectrofotometria a $570 \mathrm{hm}$, traduzindo pela absorvância, o grau presente de células ativas $^{8}$. A intensidade da coloração azul obtida, é diretamente proporcional ao número de células viáveis.

No presente trabalho, foi observado menores índices de viabilidade celular no grupo SF quando comparado aos grupos $\mathrm{SH}$ e $\mathrm{C}$.

Para tal, deve ser relembrado que ao evoluir em direção ao ponto crítico ou "volume crítico de sangramento" (VCS), devido a escassez crescente de oxigênio tissular, progressivamente, as células substituem a respiração aeróbia, pela anaeróbia, a qual produz menor quantidade de energia, com produção elevada de catabólitos celulares e dentre estes os radicais livres de oxigênio. ${ }^{13}$

Teoricamente, estes piores resultados podem ter ocorrido nos animais do grupo SF, devido a solução fisiológica de cloreto de sódio ser isotônica ao plasma. Contudo, como na fase inicial de recuperação do choque, o meio intersticial e o intracelular perderam líquidos para o espaço intravascular na tentativa de manter a pressão sistêmica, estes tornaram-se hipertônicos em relação ao plasma. ${ }^{14}$

Provavelmente, quando realizada reposição com SF, a maior parte deste foi "seqüestrado" para o interstício e espaço intracelular, que encontravam-se hipertônicos, ocorrendo um efeito de "lavagem" súbita de células em sofrimento isquêmico, e logo, ricas em RLO e citocinas. Estes mediadores, carreados através das membranas celulares, reagiram com as mesmas, tornando-as instáveis e propícias a promover a morte celular. ${ }^{6}$

Deste modo, com o evoluir da pesquisa, à partir do $3^{\circ} \mathrm{DPO}$, foram progressivamente observados meno- res índices de viabilidade celular, sendo estes mais evidentes no grupo SF (Tabela 1 e Figura 1), levando a crer que as lesões necessitam de pelo menos 48 horas para sua instalação e observação. Estes achados estão de acordo com os observados por BRITO e ACÄCIO (1999).

Devido a osmolaridade aumentada das soluções hipertônicas $\left(2.500 \mathrm{mOsm} / \mathrm{l}^{-1}\right)$ em relação ao plasma (300 mOsm / $\left.\mathrm{l}^{-1}\right)^{49}$, provavelmente houve diminuição do efeito de "lavagem celular" e menor ativação da circulação linfática em relação as soluções isotônicas, fornecendo oxigênio aos tecidos em sofrimento de modo mais lento e constante, o que favoreceu a inativação de radicais livres de oxigênio (RLO) por mecanismos fisiológicos da célula, diminuindo seu contato com as membranas $^{6}$, e deste modo viabilizando um maior número de células intestinais nesta pesquisa (Tabela 1 e Figura 1).

Deste modo, surgem em pesquisas recentes, cada vez mais indícios da participação dos produtos de degradação celular originados não só durante a isquemia, mas principalmente durante a reperfusão intestinal quando utilizadas soluções "isotônicas", que disseminados principalmente por via linfática, seriam os causadores da falência respiratória que geralmente precede a falência dos demais órgãos na IMOS.

As soluções hipertônicas, por seu mecanismo de ação, melhorariam a microcirculação tecidual, hipoativando a circulação linfática, e com isso minimizando a disseminação de produtos tóxicos para os pulmões.

De qualquer maneira, muito ainda falta ser pesquisado, até que sejam totalmente compreendidos os mecanismos envolvidos na gênese e compensação de estados de choque e suas consequiências.

\section{Conclusão}

A correção volêmica com solução de cloreto de sódio a $7.5 \%$, leva a manutenção de maior quantidade de células viáveis, no intestino delgado de ratos.

\section{Referências}

1. Tao W, Zwischenberger JB, Nguyen TT, Vertrees RA, Nutt LK, McDaniel LB, Kramer GC. Hypertonic saline/dextran for cardiopulmonary bypass reduces gut tissue water but does not improve mucosal perfusion. J Surg Res 1994; 57(6):718-25.

2. Mori ND. Os efeitos do choque hemorrágico e seu tratamento com $\mathrm{NaCl}$ a 7,5\% no acúmulo de neutrófilos nos pulmões: estudo experimental em ratos[Tese - Doutorado]. Universidade Federal de São Paulo - Escola Paulista de Medicina; 1996.

3. Velasco IT, Rocha-e-silva M. Hipertonic saline resuscitation is prevented by intracerebroventricular saralasin but not by captopril. Braz J Med Biol Res 1989; 22:237-9.

4. Sztark F, Gékière JP, Dabadie P. Effets hémodynamiques des solutions salées hypertoniques. Ann Fr Anesth Réanim 1997; $16(3): 282-91$ 
5. Steenbergen JM, Bohlen HG. Sodium hyperosmolarity of intestinal lymph causes arteriolar vasodilation in part mediated by EDRF. Am J Physiol 1993, 265:323-8.

6. Upperman JS, Deitch EA, Guo W, Lu Q, Xu D. Post hemorrhagic shock mesenteric lymph is cytotoxic to endothelial cells and activates neutrophils. Shock 1998; 10(6):407-14

7. Brito MVH, Brito NMB, Carvalho MR, Almeida AJB. Vaporizador artesanal de éter para cirurgia experimental em ratos. Acta Cir Bras 1998; 13(1) 1-5.

8. Yale CE, Torhorst JB. Critical bleeding and plasma volumes of the adult germfree rat. Lab Anim Science 1972; 22:497-502.

9. Siegel S. Estadística no paramétrica. México: Trillas; 1975.

10. Haglind E, Haljamäe H. Failure of hypertonic saline to resuscitate intestinal ischemia shock in the rat. Acta Anaest Scand 1992, 36:410-8
11. Matsuoka T, Wisner DH. Resuscitation of uncontrolled liver hemorrhage: effects on bleeding, oxygen delivery, and oxygen consumption. J Trauma 1996, 41(3):439-45.

12. Mosmann T. Rapid colorimetric assay for cellular growth and survival : application to proliferation and cytotoxicity assays. J Immunol Methods 1983, 65:55-63.

13. Marsicano LJ. Los Radicales libres. GEN 1994, 48(1):39-44.

14. Guyton AC. Tratado de fisiologia médica. 8ed. Rio de Janeiro: Guanabara Koogan; 1992.

15. Brito MVH, Acácio GJS. Lesão intestinal após isquemiarepurfusão: estudo comparativo usando sal tetrazólico (MTT) e histologia [Tese de Conclusão de Curso]. Universidade Federal do Pará; 1999.

Brito MVH, Nigro AJT, Montero EFS, Nascimento JLM, Silva PRF, Siqueira RBP. Celular viability of rat small bowel mucosa, after hypovolemic shock correction with $\mathrm{NaCl}$ 7,5\% solution. Acta Cir Bras [serial online] 2003 Jul-Aug;18(4). Available from URL: http://www.scielo.br/acb.

ABSTRACT - Purpose: Study the effect of the volemic correction with different solutions, in the mucous of the small bowel in rats. Methods: Were used 120 rats Wistar (Rattus norvegicus albinus), males, adults, seemingly healthy, with individual weight varying between 310 and 410g, originating from of the Instituto Evandro Chagas of Belém of Pará, submitted to an adaptation period of 15 days, receiving water and ration ad libitum, during the role experiment. For the research, ten animals were distributed, in groups and subgroups as following: Standard group (S), Shock group (Sh), Physiological Solution group (PS) and Hypertonic Solution Group (HS). The groups were divided in subgroups with 10 animals each, in agreement with the day of postoperative (DPO) foreseen for the euthanasis of the animals, (1st, 3rd or 7th DPO), being after this, picked material for cellular viability in every animals. Results: The group PS took less quantity viable cells. Conclusion: The volemic correction with chloride of sodium solution at $7.5 \%$, when compared the correction with chloride of sodium at $0.9 \%$ (isotonic solution), took the maintenance of larger amount of viable cells, in the small bowel in rats.

KEY WORDS - Cell survival. Shock. Hypertonic solutions. Rats.

Conflito de interesse: nenhum Fonte de financiamento: nenhuma

Correspondência:

Marcus Vinicius Henriques Brito

Travessa Apinagés, 630/201

66033-170 Belém - Pará

Tel: (91)242-5179 - Fax: (91)242-6636

mnbrito@amazon.com.br

Data do recebimento: 28/04/2003

Data da revisão: $12 / 05 / 2003$

Data da aprovação: 20/05/2003 